\title{
ON THE WEIGHTED HARDY TYPE INEQUALITY IN A FIXED DOMAIN FOR FUNCTIONS VANISHING ON THE PART OF THE BOUNDARY
}

\author{
Yu. O. Koroleva
}

Abstract. We derive and discuss a new two-dimensional weighted Hardy-type inequality in a rectangle for the class of functions from the Sobolev space $H^{1}$ vanishing on small alternating pieces of the boundary.

Mathematics subject classification (2010): 39A10, 39A11, 39A70, 39B62, 41A44, 45A05.

Keywords and phrases: Inequalities, partial differential equations, functional analysis, spectral theory, homogenization theory, Hardy-type inequalities.

\section{REFERENCES}

[1] G. A. Chechinin, Yu. O. Koroleva And L. -E. Persson, On the precise asymptotics of the constant in the Friedrich's inequality for functions, vanishing on the part of the boundary with microinhomogeneous structure, J. Inequal. Appl., 2007 (2007), Article ID 34138, 13 pages.

[2] G. A. Chechinin, Yu. O. Koroleva, A. Meidell and L. -E. Persson, On the Friedrichs inequality in a domain perforated nonperiodically along the boundary. Homogenization procedure. Asymptotics in parabolic problems, Russ. J. Math. Phys., 16, 1 (2009), 1-16.

[3] D. Gilbarg And N. Trudinger, Elliptic Partial Differenrial Equations of Second Order, SpringerVerlag, 1983.

[4] P. Hajlasz, Pointwise Hardy inequalities, Proc. Amer. Math. Soc., 127 (1999), 417-423.

[5] G.H.Hardy, J.E. Littlewood And G.Pólya, Inequalities, Cambridge Mathematical Library (Reprint of the 1952 edition ed.), Cambridge: Cambridge University Press, 1988. Math. Anal., 109 (1934), 463-487, 685-713.

[6] I. S. KAC AND M. G. KREIN, Criteria for discreteness of the spectrum of a singular string, Izv. Vyss. Uchebn. Zaved. Mat., 2 (1958), 136-153.[in Russian]

[7] J. Kinnunen And R. KoRTE, Characterizations for Hardy's Inequality, Around the Research of Vladimir Maz’ya, International Mathematical Series, 11 (2010), 239-254.

[8] V. Kokilashvili, A. Meskhi And L.-E.Persson, Weighted Norm Inequalities For Integral Transforms With Product Kernals, Nova Science Publishers Inc (United States), 2009.

[9] A. KUFNER, Weighted Sobolev Spaces, John Wiley and Sons, 1985.

[10] A. Kufner, L. Maligranda And L.-E. Persson, The Hardy Inequality. About its History and some Related Results, Vydavetelsky Servis Publishing House, Pilsen, 2007.

[11] A. KUfNER AND L.-E. Persson, Weighted Inequalities of Hardy Type, World Scientific, New JerseyLondon-Singapore-Hong Kong, 2003.

[12] V. G. MaZ’JA, Sobolev spaces, Translated from the Russian by T.O. Shaposhnikova, Springer Series in Soviet Mathematics, Springer-Verlag, Berlin, 1985.

[13] J. NEČAS, Sur une méthode pour résourde les équations aux dérivées partielle du type elliptique, voisine de la variationelle, Ann. Scuola Norm. Sup. Pisa, 16 (1962), 305-362.

[14] B. OPIC AND A. KUfNER, Hardy-Type Inequalities, Longman, Harlow, 1990.

[15] W. ZIEMER, Weakly Differentiable Functions, Graduate Texts in Mathematics 120, Springer-Verlag, 1989.

[16] A. Wannebo, Hardy Inequalities and Imbedding in Domains Generalizing $C^{0, \lambda}$ Domains, Proc. Amer. Math. Soc., 122 (1994), 1181-1190.

Reprint of the sixth (1980) edition. Classics in Mathematics, Springer-Verlag, Berlin, 1995. 